\title{
CORRESPONDENCE
}

Sodium Nitroprusside in Anaesthesia

H. A. Condon, F.F.A.R.C.S.; M. P. Coplans,

F.F.A.R.C.S.; D. A. B. Hopkin, F.F.A.R.C.S. . . 38

Solitary Pulmonary Nodules

J. B. Jameson, F.R.A.C.R....

G.P. Obstetrics in the Future

Malaria Vaccines

K. N. Brown, PH.D............... 39

Withdrawal Symptoms in Newborn

Infants of Epileptic Mothers

M. J. Erith, M.B..............

Non-invasive Investigations of the Brain

P. J. Ell, M.D.SC, and others ............

Fluorinated Corticosteroids and Dermatophytosis

J. N. Burry, M.R.C.P.ED

Improving the Service

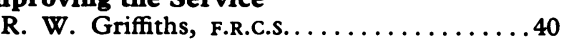

Randomization

J. A. Lewis, M.A.

Safer Cigarettes

M. A. H. Russell, M.R.C.PSYCH.
Diagnosis in the Elderly

C. Reisner, M.в.................41

The Suicide Profile

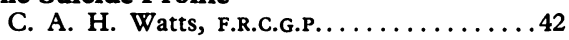

econdary Syphilis and Hepatitis

J. R. Sewell, M.R.C.P., and M. A. Ahmed,

M.R.C.PATH. $\ldots \ldots \ldots \ldots \ldots \ldots \ldots \ldots \ldots 42$

Abortion (Amendment) Bill

J. F. B. Hird, M.R.C.G.P., and others. . . . 42 Picking a Diuretic

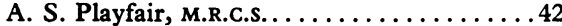

Defence of the French Language

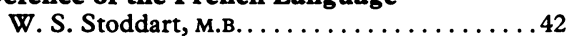

Genital Medicine

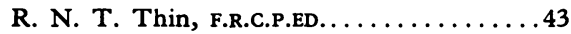

Profits from Propaganda

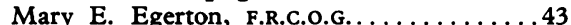

G.M.C. and Indian Qualifications

A. K. Varshneya, F.R.C.S.ED.........43

Overseas Doctors and the E.E.C.

S. K. Roy, M.D................43

B.M.A.: Need for Radical Change

H. Gordon, M.R.C.G.P.............443
Junior Hospital Stafi Contract

A. J. Ahmad, M.R.C.P., and others; S. R.

Brennan, M.R.C.P.; R. H. A. Campbell,

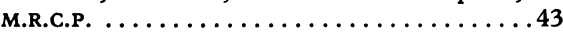

Development Allowance and Inflation

J. Callander, M.B..............44

Related Ancillary Staff

B. J. Stafford, M.R.C.G.P............44

Too Many Specialist Organizations ?

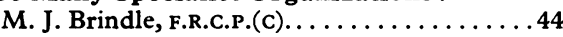

Points from Letters Value of G.P. Investigations in Diagnosis of Medical Outpatients ( $K$. A Harden); Agammaglobulinaemia or Hypogammaglobulinaemia? (D. Gill); Chronic Paronychia (Elizabeth J. F. Harries); Side Effects of Methyldopa (J. Mackay-Dick); The Modern Medical Student (M. St. G. Wheeley); Clinician and Scientist (K. Norcross); Better Medical Writing (J. S. Bradshaw); Kidneys for Transplantation (Audrey W. M. Ward); Postal Questionnaires (B. Gray); Genitourinary Medicine (E. H. Sims)................45
Correspondents are urged to write briefly so that readers may be offered as wide a selection of letters as possible. So many are now being received that the omission of some is inevitable. Letters should be signed personally by all their authors.

\section{Sodium Nitroprusside in Anaesthesia}

SIR,-Your leading anticle (7 June, p. 524) rightly commends sodium nitroprusside as an agent for hypotensive anaesthesia, but in suggesting possible indications, no reference was made to contraindications and alternative methods. May I comment on two aspects?

Firstly, regarding radical head and neck surgery, many such patients exhibit known contraindications to hypotensive anaesthesia for example, circulatory disorders. The risks are substantially increased if such contraindications are ignored, as in a case reported by Forrester ${ }^{1}$ of paraplegia following laryngectomy under hypotensive anaesthesia, the patient being a known hypertensive.

Secondly, microsurgery of the ear. To obtain adequate microscopic haemostasis by hypotensive methods $\mathrm{Kerr}^{2}$ considered the systolic blood pressure should be taken to $40 \mathrm{~mm} \mathrm{Hg}$ or below. Deacock, 3 however, has shown what can be achieved by a meticulous conventional technique-that is, an average total blood loss per stapedectomy of $1 \mathrm{ml}$. He found hypotensive methods were needed in $8 \%$ of stapedectomies, $10 \%$ of myringoplasties, and $22 \%$ of tympanoplasties.

The advocates of hypotensive anaesthesia have suggested that the method is safe in the hands of skilled workers. However, private conversation with practitioners in this field usually reveals, in each area, "a case" which has done badly when the hypotensive method has been used. Wylie, ${ }^{4}$ in a recent review of 66 cases of cardiac arrest related to anaesthesia and reported to the
Medical Defence Union, considered four of these cases to be due to deliberate hypotension. The incidence of permanent neurological damage is very difficult to assess.

The completely dry operative field should not be expected or requested by surgeons. Such a result can be achieved only by using excessive degrees of hypatension. In my opinion the anaesthetist should adopt a cautious attitude towards controlled hypotension; complications may be rare, but the consequences for the individual patient can be disastrous.-I am, etc.,

H. A. CONDON Royal National Throat, Nose and Ear Hospital,
London W.C.1

1 Forrester, A. C., Anaesthesia, 1959, 14. 388. 2 Kerr, A. R., British Medical fournal, $1964,3,473$. 3 Deacock, A. R., Proceedings of the Royal Society of Medicine, 1971, 64, 1226. Royal College of Surgeons of England, $1975,56,171$.

SIR,-Y Your leading article (7 June, p. 524), draws attention to the incidence of "resistance" to the drug necessitating high dosage, with resultant increase in plasma cyanide level and possible dangerous sequelae. I believe that many, if not all, of these so-called "resistant" cases appear to be so simply because the nitroprusside is given by slow infusion into the lower arm or hand, with the patient tilted head upwards. Profound vasodilatation in the dependent arm may result in pooling of the drug peripherally, total absorption into the central circulation being delayed until the head-up tillt has been discontinued and limb movements have commenced-that is, until the recovery period.

I would like to suggest that sodium nitroprusside, and certain other drugs commonly given by slow intravenous infusion, should always be administered through the proximal (nearest to patient) limb of an "F" connexion so that they may be continuously washed into the cinculation rapidly by an inert solution attached to the distal limb of the connexion.-I am, etc.,

St. George's Hospital,

Michael P. Coplans

SIR,-I find it difficult to understand why anyone can recommend the routine use of sodium nitroprusside to produce hypotension during anaesthesia in view of the evident dangers of the method.

The casual reference in your leading article (7 June, p. 524) to the "few deaths that have occurred both in 'resistant' patients and in experiments on baboons" is sufficient in itself to condemn the method. Any doubts one had should surely be dispelled by the subsequent sentence: "Severe metabolic acidosis, cardiac arrhythmias, and a deepening level of unconsciousness appears to be the pattern in these cases; if the acidosis is promptly treated and the drug withdrawn then recovery is possible" (my italics) -but not certain?

Much is made of the diagnosis and treatment of "metabolic acidosis," which is surely a euphemism for cyanide poisoning. Professor D. G. McDowall and his colleagues ${ }^{1}$ have shown this does not take place until 90 minutes after toxic levels of sodium nitroprusside have been reached, during which time further amounts of nitroprusside could be given with fatal consequences. 